\title{
Evaluation of five different immersion fixatives for light microscopic studies of liver tissue in Atlantic salmon Salmo salar
}

\author{
L. Speilberg ${ }^{1}, \varnothing$ Evensen $^{1}$, B. Bratberg ${ }^{1}$, E. Skjerve ${ }^{2}$ \\ ${ }^{1}$ National Veterinary Institute, PO Box 8156, Dep, N-0033 Oslo, Norway \\ ${ }^{2}$ Norwegian College of Veterinary Medicine, PO Box 8146, Dep, N-0033 Oslo, Norway
}

\begin{abstract}
Five aldehyde-containing fixatives were compared with regard to maintenance of light microscopic morphology in the liver of Atlantic salmon Salmo salar L. Parallel liver samples from adult fish were fixed in each fixative, processed routinely, sectioned, and stained with H\&E (hematoxylin and eosin) and PAS (periodic acid-Schiff reaction). Coded H\&E slides were evaluated by 3 independent observers according to defined morphological criteria, including appearance of hepatic parenchyma, vasculature, bile ducts, and connective tissue. The data obtained were subjected to statistical treatment. The different fixatives' abilities to preserve cytoplasmic glycogen were assessed from PAS-stained sections. $10 \%$ formalin with modified Millonig's phosphate buffer and Davidson's fluid were found to be most effective in maintaining liver morphology at the light microscopic level. $10 \%$ formalin with modified Millonig's phosphate buffer also provided the best demonstration of hepatocellular cytoplasmic glycogen deposits. The current study also illustrates the influence on fixative evaluation of varying amounts of hepatocellular glycogen deposits, and of personal preferences by the observers.
\end{abstract}

KEY WORDS: Atlantic salmon · Fish · Fixation - Fixative evaluation - Liver - Morphology

\section{INTRODUCTION}

Diagnostics and research on fish diseases have increased greatly in recent decades with the expansion of commercial fish cultivation. Moreover, fish are used as model systems in toxicology and cancer research (Hacking et al. 1978, Ishikawa \& Takayama 1979, Couch 1991), and as indicators of pollution in the aquatic environment (Mearns \& Sherwood 1974, Sinnhuber et al. 1977, Bucher et al. 1992). Histopathological studies comprise an important part of all these disciplines, with tissue fixation as a pivotal basis. Therefore, basic studies performed to acquire adequate methods of fixation are highly relevant to applied research on fish diseases

The purpose of tissue fixation is to preserve morphology as close to the living state as possible (Hopwood 1985). The ideal fixative should induce minimal changes morphologically and chemically, and protect against such changes in the subsequent procedures.
Such a fixative is probably elusive (Doyle \& O'Leary 1992), but cross-linking, aldehyde-based fixatives have been considered to approach the desired qualities when evaluated for fixation of mammalian tissue (Jones 1973).

Despite the fact that there are differences in tissue osmolarity, and that the autolysis in fish is very rapid compared to that in homeotherms, controlled fixation studies of the type performed by various investigators on mammal tissues (McDowell \& Trump 1976, Davenport \& Ball 1979) have, to our knowledge, not been undertaken in fish. The obvious need for such studies has been pointed out by previous authors (Hinton et al. 1984). Application of perfusion techniques in fish (Hinton 1974) has in many instances proved superior to immersion with regard to morphological appearance. However, the simplicity of immersion still makes it the method of choice in many circumstances, e.g. in routine diagnostics and in studies including large numbers of fish. 
The aim of this investigation was to evaluate and compare 5 different immersion fixatives for use in light microscopic examination of liver morphology in Atlantic salmon Salmo salar L. A statistical approach was used in interpreting observations.

\section{MATERIALS AND METHODS}

Fixative preparation. This study involved 5 different fluids, 4 of which contained formalin (formaldehyde solution min. $37 \%$, stabilized with 8 to $12 \%$ methanol; Merck; Germany).

Bouin's fluid (Bullock 1989): $50 \mathrm{ml}$ formalin and $10 \mathrm{ml}$ glacial acetic acid were added to $150 \mathrm{ml}$ of saturated, aqueous picric acid (picric acidi Merck, Germany).

Davidson's fluid (Shaw \& Battle 1957): $40 \mathrm{ml}$ formalin, $20 \mathrm{ml}$ glycerol, $20 \mathrm{ml}$ glacial acetic acid, and $60 \mathrm{ml}$ absolute alcohol were added to $60 \mathrm{ml}$ tap water.

$10 \%$ formalin with modified Millonig's phosphate buffer (Carson et al. 1973): $18.6 \mathrm{~g}$ sodium phosphate monobasic were dissolved in $500 \mathrm{ml}$ tap water. $4.2 \mathrm{~g}$ sodium hydroxide dissolved in $400 \mathrm{ml}$ water and $100 \mathrm{ml}$ formalin were then added, and the $\mathrm{pH}$ adjusted to 7.2. The osmolality of the phosphate buffer was $310 \mathrm{mOsm} \mathrm{kg}{ }^{-1}$, determined by freezing point depression in a Fiske One-Ten Osmometer (Fiske Associates, USA).

$10 \%$ formalin $+1 \%$ glutaraldehyde in $0.1 \mathrm{M}$ phosphate buffer (MCDowell \& Trump 1976): $11.6 \mathrm{~g}$ sodium phosphate monobasic were dissolved in $860 \mathrm{ml}$ tap water, and $2.7 \mathrm{~g}$ sodium hydroxide, $40 \mathrm{ml}$ glutaraldehyde (glutardialdehyde solution $25 \%$; Merck, Germany) and $100 \mathrm{ml}$ formalin then added. The $\mathrm{pH}$ was adjusted to 7.2. The osmolality of the buffer was 205 mOsm kg ${ }^{-1}$

Modified half-strength Karnovsky's fluid (Ito and Karnovsky 1968): $20.0 \mathrm{~g}$ paraformaldehyde powder (paraformaldehyde; Merck, Germany) was added to $300 \mathrm{ml}$ water, and heated to $70^{\circ} \mathrm{C}$ while stirring After cooling, $11.6 \mathrm{~g}$ sodium phosphate monobasic, and $2.7 \mathrm{~g}$ sodium hydroxide dissolved in $600 \mathrm{ml}$ tap water, were added, together with $100 \mathrm{ml} 25 \%$ glutaraldehyde and $0.2 \mathrm{~g}$ picric acid. The $\mathrm{pH}$ was adjusted to 7.2 . The osmolality of the buffer was 205 mOsm kg-1.

Fish and rearing conditions. Five sexually immature individuals of Atlantic salmon ranging in size from 0.85 to $1.5 \mathrm{~kg}$ were included in the investigation. The fish were obtained from a commercial fish farm on the southern coast of Norway, situated in an area with no previous reports of diseases liable to interfere with liver morphology, such as furunculosis or infectious salmon anemia. All fish were of the same descent and age group, and had been transferred to seawater 15 mo prior to sampling. Fish were fed a standard commercial diet. Fixation was performed at an ambient temperature of $14^{\circ} \mathrm{C}$. Water temperature was $13^{\circ} \mathrm{C}$.

Tissue sampling, processing, and staining. The fish were collected while feeding Each individual was killed by a blow to the head, and liver tissue samples collected immediately. A sagittal slice $1 \mathrm{~cm}$ thick was cut from the organ and diced into pieces approximately $1 \mathrm{~cm}^{3}$ in size. Two pieces were then immersed in each of the 5 fixatives (volume approximately $20 \mathrm{ml}$ ). The whole operation took less than 1 min. Following fixation for $48 \mathrm{~h}$, samples were dehydrated via a graded alcohol-xylene series (Table 1) using a Citadel 2000 automatic processor (Shandon Southern Products Ltd, England), and embedded in paraffin wax (Vogel Histo-Comp ${ }^{(1)}$ ).

Table 1. Processing schedule for the fixed liver samples from Salmo salar

\begin{tabular}{|lcc|}
\hline Fluid & Time & Temperature \\
\hline Alcohol $70 \%$ & $30 \mathrm{~min}$ & $20^{\circ} \mathrm{C}$ \\
Alcohol $80 \%$ & $60 \mathrm{~min}$ & $20^{\circ} \mathrm{C}$ \\
Alcohol $96 \%$ & $30 \mathrm{~min}$ & $20^{\circ} \mathrm{C}$ \\
Alcohol $96 \%$ & $60 \mathrm{~min}$ & $20^{\circ} \mathrm{C}$ \\
Absolute alcohol & $45 \mathrm{~min}$ & $20^{\circ} \mathrm{C}$ \\
Absolute alcohol & $60 \mathrm{~min}$ & $20^{\circ} \mathrm{C}$ \\
Xylene & $60 \mathrm{~min}$ & $20^{\circ} \mathrm{C}$ \\
Xylene & $60 \mathrm{~min}$ & $20^{\circ} \mathrm{C}$ \\
Paraffin wax & $60 \mathrm{~min}$ & $60^{\circ} \mathrm{C}$ \\
Paraffin wax & $5 \mathrm{~h}$ & $60^{\circ} \mathrm{C}$ \\
\hline
\end{tabular}

Two sections, 5 to $6 \mu \mathrm{m}$ thick, were cut from each sample and stained with hematoxylin and eosin (H\&E), yielding a total of 100 slides for examination.

In addition, periodic acid-Schiff (PAS)-staining was performed to evaluate the preservation of cytoplasmic glycogen, confirmed by saliva diastase digestion (Bancroft \& Stevens 1975).

Evaluation of H\&E slides. The $H \& E$ slides were coded, ensuring unknown identity until the examination was completed. Each slide was then evaluated individually by 3 different examiners (L.S., Ø.E., B.B.). The variables observed (response variables) and the principal criteria for their evaluation were as follows:

(1) Morphological appearance of hepatocyte nuclei: Should be smooth and have a round or oval shape, with a relatively even distribution of chromatin.

(2) Morphological appearance of hepatocyte cytoplasm: Should be distinctly eosinophilic, homogeneous, and well outlined. Pronounced shrinkage disfavoured

(3) Morphological appearance of vasculature, including sinusoids: Sinusoids should be readily recognizable, and have a distinct endothelium. 
(4) Morphological appearance of bile ducts: Epithelial cells should be well outlined, with wellpreserved brush border. Washed-out musculature disfavoured.

(5) Morphological appearance of connective tissue: Should be eosinophilic. Swelling disfavoured

(6) Artifacts: Included marginal effects, shrinkage, formol pigment, washed-out appearance of erythrocytes, tears and holes.

(7) General judgment: A general evaluation of the slide, including an overall judgement of tissue architecture and cell morphology.

Statistical analysis. Each H\&E evaluation was expressed on a $100 \mathrm{~mm}$ visual analog scale (VASS) ${ }^{\circ}$, producing variables statistically treated as being continuous. To avoid a situation where the evaluations of an observer using the whole width of the VAS exerted a greater influence on the overall result than those of an observer concentrating his marks in the midfield, corrected units (CU) were calculated. Each observation of a parameter was subtracted from the examiner's mean and divided by the examiner's standard deviation for that parameter.

Data were checked for normality and analyzed by means of the ANOVA procedure (analysis of variance) in SAS (SAS Institute, Inc., Cary, NC, USA). An analysis of variance involves testing how much of the variation between observations is due to different 'factors' (grouping variables). Results are given as 'F-values'. Factors to be studied in our experiment were Fixative (5 levels) and Fish (5 levels), including interactions Due to the use of corrected units, grouping observations according to Examiner ( 3 levels) would produce identical means and standard deviations for each group. Consequently, $F$-values for the factor Examiner would become zero. This factor was therefore only included in the study of interactions.

Response parameter means for each Fixative group were compared by multiple $t$-tests $(\alpha=0.05$ for each comparison).

Evaluation of PAS slides. For PAS-stained sections, the fixatives were ranked with regard to preservation of cytoplasmic glycogen.

\section{RESULTS}

\section{Comparison of fixatives}

All sections were free of pathological changes. $10 \%$ formalin gave the highest $\mathrm{CU}$ mean for parameter 7

\footnotetext{
- A visual analog scale consists of a horizontal straight line. Each evaluation is expressed as a mark on the scale, good results to the right, less satisfactory to the left. The scales are then read using a ruler
}

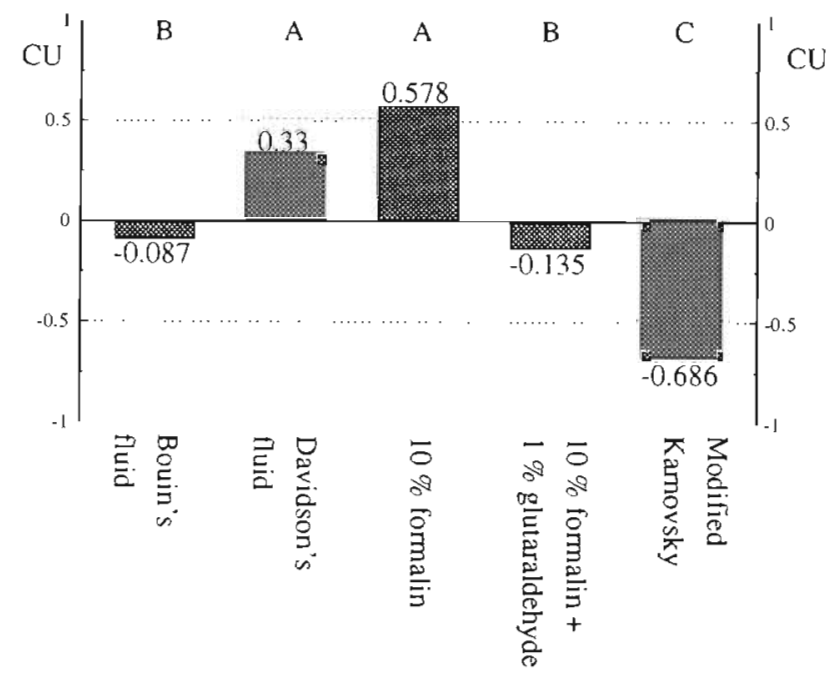

Fig. 1. Multiple $t$-test. Means for parameter 7 (General judgment), for the 5 different fixatives. Fixatives with the same letter (A, B, C) are not significantly different. CU: corrected units (see text). Grand mean $=0, \mathrm{SD}=1, \alpha=0.05$

(General judgment), though not significantly better than Davidson's fluid (Fig. 1). The CU means obtained for the same parameter with Bouin's fluid and the mixture of $10 \%$ formalin and $1 \%$ glutaraldehyde were significantly lower than for those 2 fixatives (Fig. 1), while that for modified Karnovsky was significantly lower than for all other fixatives (Fig. 1).

Group means for the remaining 6 parameters are presented in Fig. 2. Bouin's and Davidson's fluids gave excellent results with regard to uniformity between hepatocytes throughout the liver (i.e. no marginal effects), but caused swelling of connective tissue and a washed-out appearance of erythrocytes (Figs. 3 \& 4). Nuclei and cytoplasm were well outlined However, using Bouin's fluid, homogeneity of nucleoand cytoplasm was suboptimal. Mechanical artifacts i.e. tears and holes, also constituted a problem with this fixative. $10 \%$ formalin gave good results for all parameters; its major drawback was the induction of moderate shrinkage towards the centre of the block (Fig. 5). The addition of glutaraldehyde to $10 \%$ formalin, and dilution of the phosphate buffer, had a negative impact on all parameters (Figs. 1 \& 2). A broad marginal zone with swollen hepatocytes and pronounced shrinkage in the centre were constant findings with this fixative (Fig. 6). These negative effects were even more markedly expressed with modified Karnovsky (not shown).

Evaluation of PAS-stained slides (Figs. 7 to 12) indicated that $10 \%$ formalin gave the best results, also with regard to the conservation of cytoplasmic glycogen, followed by $10 \%$ formalin with $1 \%$ glutaralde- 


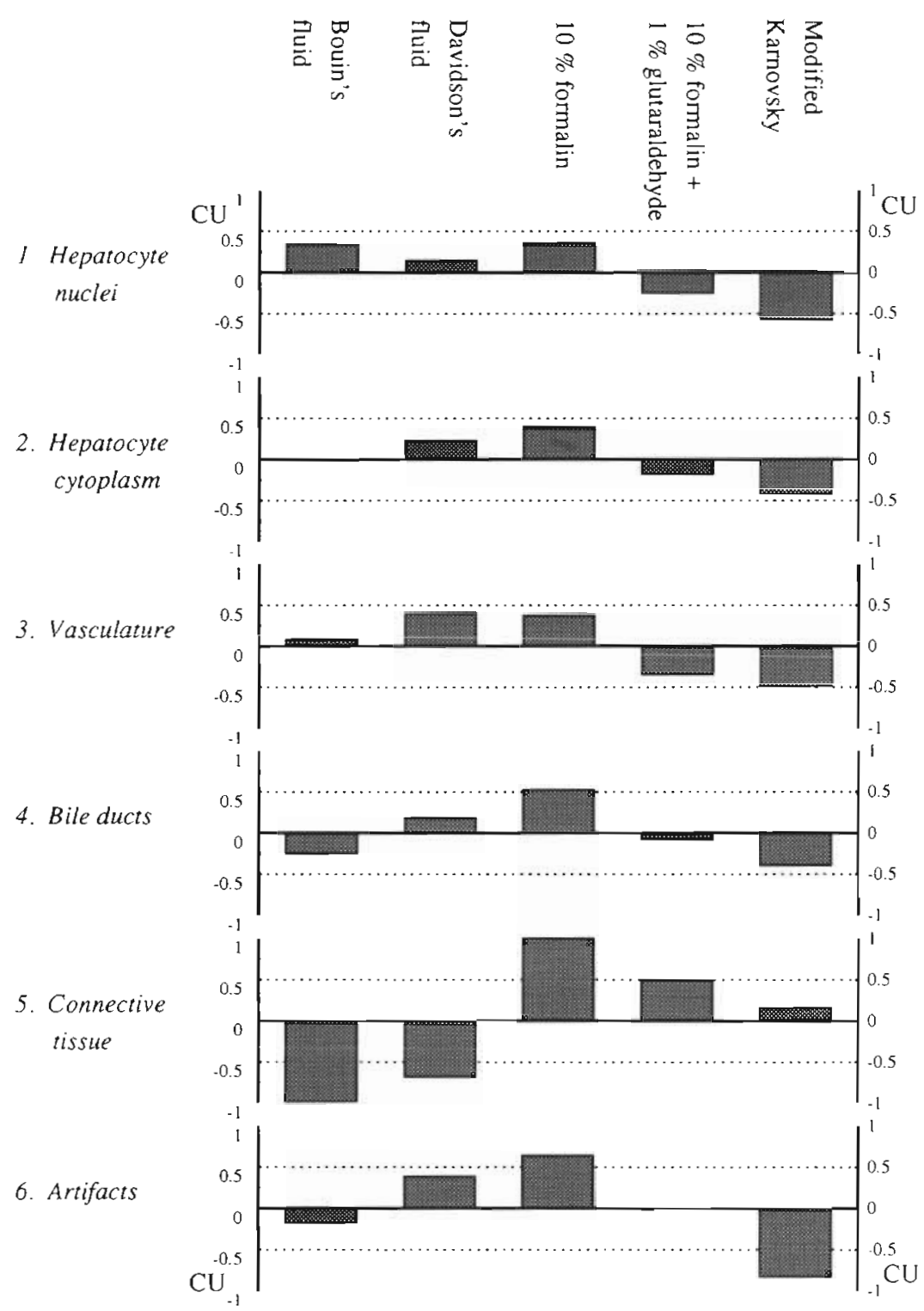

Fig. 2. Means for parameters 1 to 6 for the 5 different fixatives. CU: corrected unit (see text). Grand mean $=0, S D=1$
Analysis of variance

Fixative constituted the major source of variation for most response parameters, as shown in Table 2 .

However, there was also considerable variation between fish, particularly with regard to the parameters 2 (Hepatocyte cytoplasm), 3 (Vasculature), and 7 (General judgment). This may in part have been caused by variation in the amount of cytoplasmic glycogen deposits present in the liver, a theory supported by the fact that fish with the least glycogen, as judged from PAS-stained sections, achieved the best results for these 3 parameters.

Interactions were small compared to the other variance components. However, there were significant interactions between Fixative and Fish for a number of parameters (Table 2). This may again have been due to the differences in glycogen load, combined with the fixatives' varying abilities to retain glycogen. The interaction between Examiner and Fixative illustrates the way different evaluators prefer different fixatives (Table 3 ).

\section{DISCUSSION}

The results obtained in this study indicate that phosphate-buffered formalin and Davidson's fluid provided the best maintenance of liver morphology at the light microscopic level. These findings are in concert with those presented in the preliminary hyde, and modified Karnovsky. Optimal PAS-positive staining of cytoplasm was, however, always restricted to a narrow peripheral zone of the slide. Bouin's fluid and Davidson's fluid gave very poor results in this respect. study on fathead minnow Pimephales promelas Rafinesque liver and intestine by Hinton \& Pinkstaff (Hinton et al. 1984), who however also included Bouin's fluid in their selection of fixatives. Phosphatebuffered formalin and Bouin's fluid are probably the

Figs. 3 to 6. Salmo salar. Liver from 1. Atlantic salmon, fixed in 4 different fluids. Light micrographs of H\&E-sta.ned sections; $\times$ 333. Fig. 3. Bouin's fluid. Hepatocyte cytoplasm and nuclei well outlined. Moderate margination and clumping of chromatin, and suboptimal homogeneity of cytoplasm. Marked swelling of perivenous connective tissue (arrow), and washed-out appearance of erythrocytes. Fig. 4. Davidson's fluid. Sinusoids, hepatocyte cytoplasm, and nuclei are well outlined. Moderate margination and clumping of chromatin. Marked swelling of perivenous connective tissue (arrow), and washed-out appearance of erythrocytes. Fig. 5. $1.0 \%$ formalin. Hepatocyte cytoplasm and nuclei homogeneous and well outlined. Moderate shrnkage of hepatocytes. Fig. $6.10 \%$ formalin $+1 \%$ glutaraldehyde. Severe shrinkage of hepatocytes 


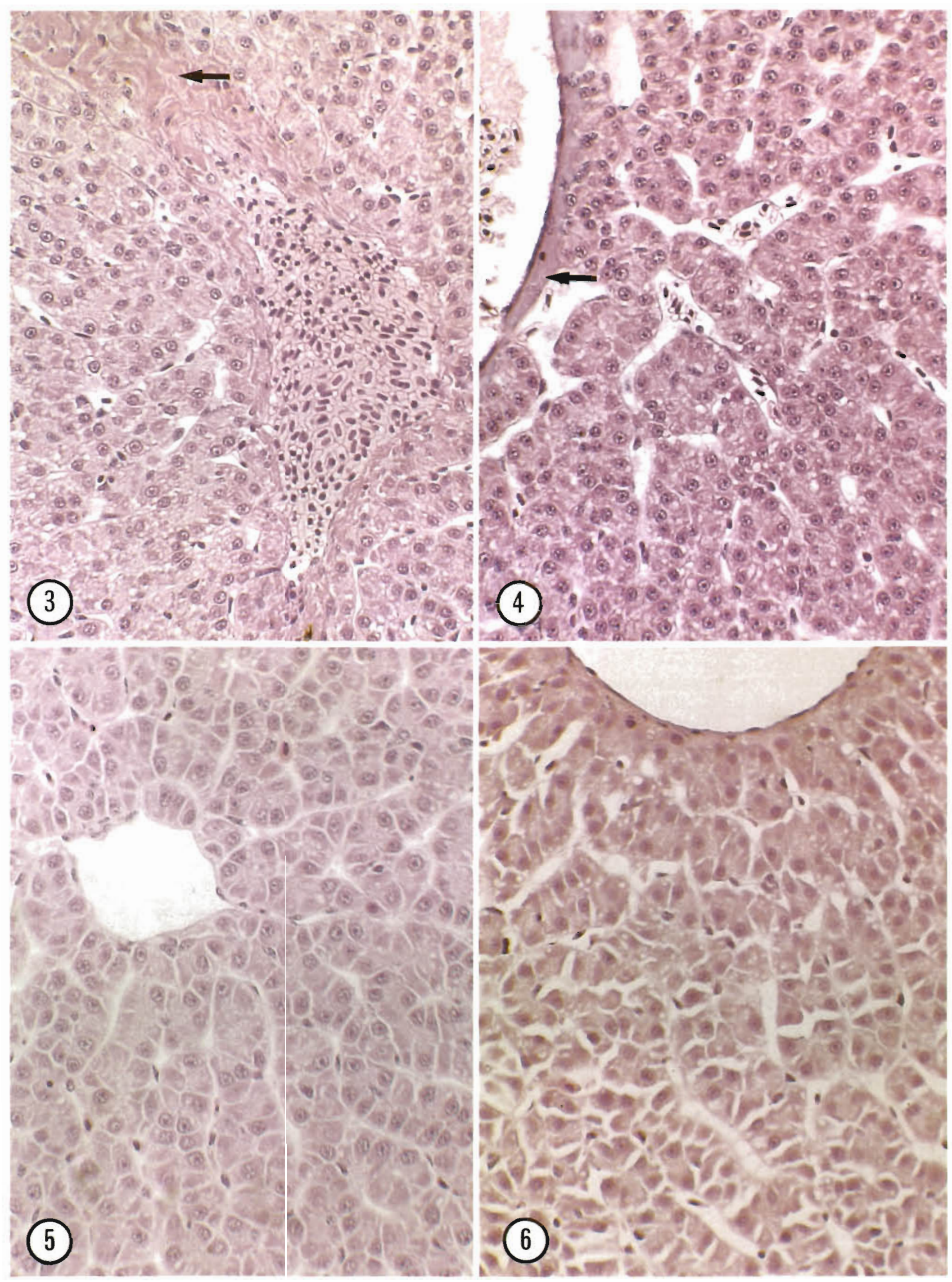


Table 2. Analysis of variance for parameters 1 to 7 F-values given are measures of the variance caused by the various factors. Italic values are not significant at the 0.05 level

\begin{tabular}{|c|c|c|c|c|c|}
\hline \multirow[t]{2}{*}{ Parameter } & \multicolumn{5}{|c|}{ Factors } \\
\hline & Fixative & Fish & $\begin{array}{c}\text { Interaction } \\
\text { Fixative } \\
\times \text { Fish }\end{array}$ & $\begin{array}{l}\text { Interaction } \\
\text { Fish } \times \\
\text { Examiner }\end{array}$ & $\begin{array}{l}\text { Interaction } \\
\text { Fixative } x \\
\text { Examiner }\end{array}$ \\
\hline (1) Hepatocyte nuclei & 12.46 & 7.17 & 1.84 & 0.23 & 1.86 \\
\hline (2) Hepatocyte cytoplasm & 9.25 & 23.12 & 2.23 & 0.34 & 2.31 \\
\hline (3) Vasculature \& sinusoids & 15.30 & 18.09 & 2.38 & 0.61 & 4.08 \\
\hline (4) Bile ducts & 9.88 & 5.81 & 2.80 & 1.00 & 3.18 \\
\hline (5) Connective tissue & 107.6 & 7.10 & 1.51 & 0.92 & 4.43 \\
\hline (6) Artifacts & 29.52 & 2.08 & 1.49 & 1.17 & 5.60 \\
\hline (7) General judgment & 21.76 & 11.45 & 2.83 & 0.32 & 3.21 \\
\hline
\end{tabular}

Table 3. Ranking of fixatives, using means for parameter 7 (General judgment). Total rank, and ranking based on examiner's individual data are shown

\begin{tabular}{|c|c|c|c|c|}
\hline Fixative & Total rank & Examiner 1 & Examiner 2 & Examiner 3 \\
\hline $10 \%$ formalin & 1 & 1 & 1 & 2 \\
\hline Davidson's fluid & 2 & 3 & 2 & 1 \\
\hline $\begin{array}{l}\text { Bouin's fluid } \\
10 \% \text { formalin }\end{array}$ & 3 & 5 & 3 & 3 \\
\hline $\begin{array}{l}+1 \% \text { glutarald. } \\
\text { Modified }\end{array}$ & 4 & 2 & 4 & 4 \\
\hline Karnovsky & 5 & 4 & 5 & 5 \\
\hline
\end{tabular}

most widely used fixatives in fish pathology. Most authors consider phosphate-buffered formalin the fixative of choice for general use (Bullock 1989, Ferguson 1989), whereas the qualities of Bouin's fluid are a matter of some controversy. Ferguson (1989) points out the usefulness of the latter for fixation of eyes, gills, skin, and whole fish because of its demineralizing properties. Bullock (1989), on the other hand, does not recommend Bouin's for skin preparations, maintaining that it makes scale cutting more difficult. Descriptions of its shrinkage properties span from 'little' (Culling et al. 1985, Bullock 1989) to 'considerable' (Hopwood 1990). In this study, shrinkage of cells using Bouin's fluid was not observed to exert any major negative influence on the liver morphology. The excellent staining properties of tissues fixed in Bouin's fluid with trichrome methods are well known, but overfixation may represent a problem in practical use (Bullock 1989). Davidson's fluid was first used with marine organisms by Shaw \& Battle (1957), but has gained limited ground in fish pathology. However, having many of the favourable properlies of Bouin's fluid, such as rapid penetration and demineralization, and fewer of its negative effects, Davidson's fluid possibly deserves to be re-evaluated and may well then achieve a position as a fixative of choice in fish pathology.

The fixatives containing a mixture of formaldehyde and glutaraldehyde are potential media for combined use in light and electron microscopy. McDowell \& Trump (1976) recommended the combination of $10 \%$ formalin and $1 \%$ glutaraldehyde, based on experiments on rat organs. In a series of studies (Hampton et al. 1985, 1988, 1989), modified half-strength Karnovsky's fluid was used, and excellent light and electron micrographs of rainbow trout Oncorhynchus mykiss liver were presented. However, fixation was performed by portal perfusion, and light micrographs showed tissue embedded in plastic or epoxy material only. Extrapolation to immersion-fixed, paraffin-embedded tissues is most likely of limited value. In the present investigation, light microscopic appearance excluded these 2 fixatives as alternatives for routine use on salmon liver.

Fixation is a complex series of chemical events not fully understood, making attempts to explain the observed differences in our study difficult. This is most certainly true concerning changes in cell and tissue

Figs. 7 to 12. Salmo salar. Liver from 1 Atlantic salmon, fixed in 5 different fluids. PAS-stained sections, illustrating differences in glycogen preservation. Light micrographs from the subcapsular area; $\times 333$. Fig. 7. Bouin's fluid. Vacuolated cytoplasm devoid of PAS-positive material. Fig. 8 . Davidson's fluid. Glycogen present only in the outermost zone, extending only a few cells deep. Fig. $9.10 \%$ formalin. Good preservation of glycogen throughout the field. Four fields of view (using a $25 \times$ objective) below the surface; however, glycogen retention was markedly reduced. Figs. 10 \& 11. $10 \%$ formalin $+1 \%$ glutaraldehyde (Fig. 10), and modified Karnovsky (Fig. 11). Good retention of glycogen in the subcapsular zone, gradually diminishing already from the deeper half of the field. Fig. 12. Modified Karnovsky. Saliva-diastase-treated section. PAS-positive material is removed, confirming its glycogen nature 


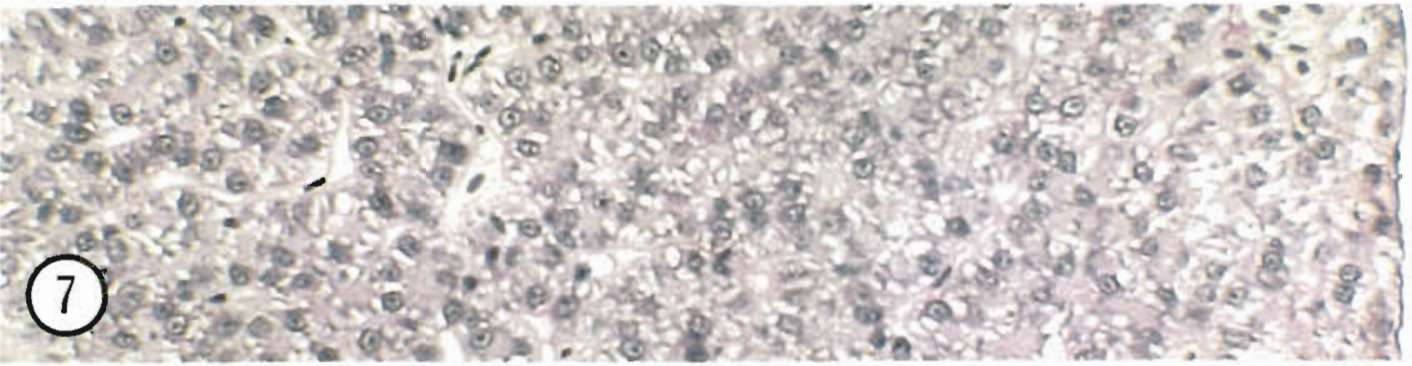

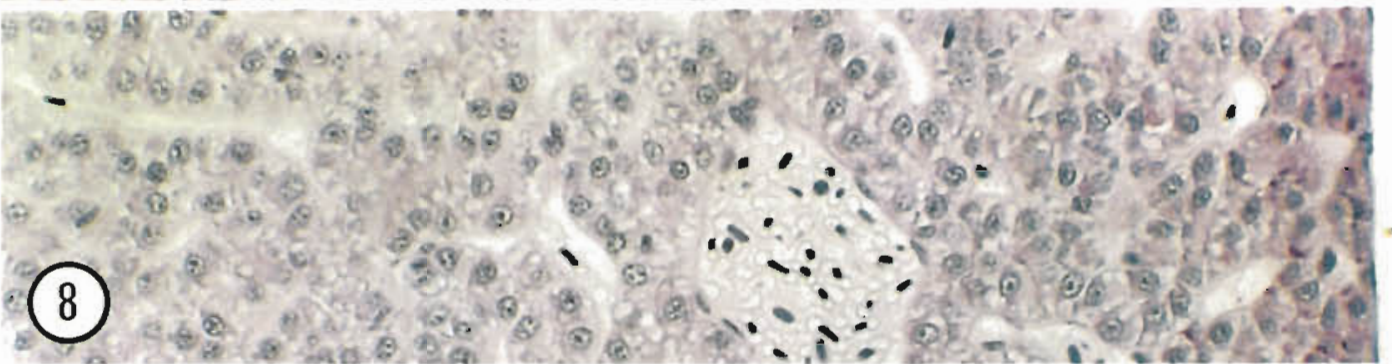

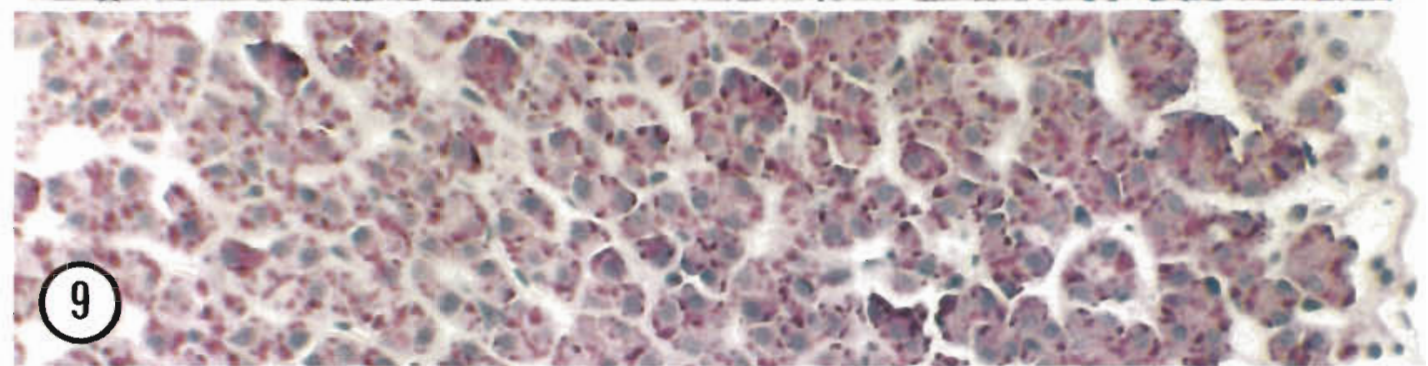

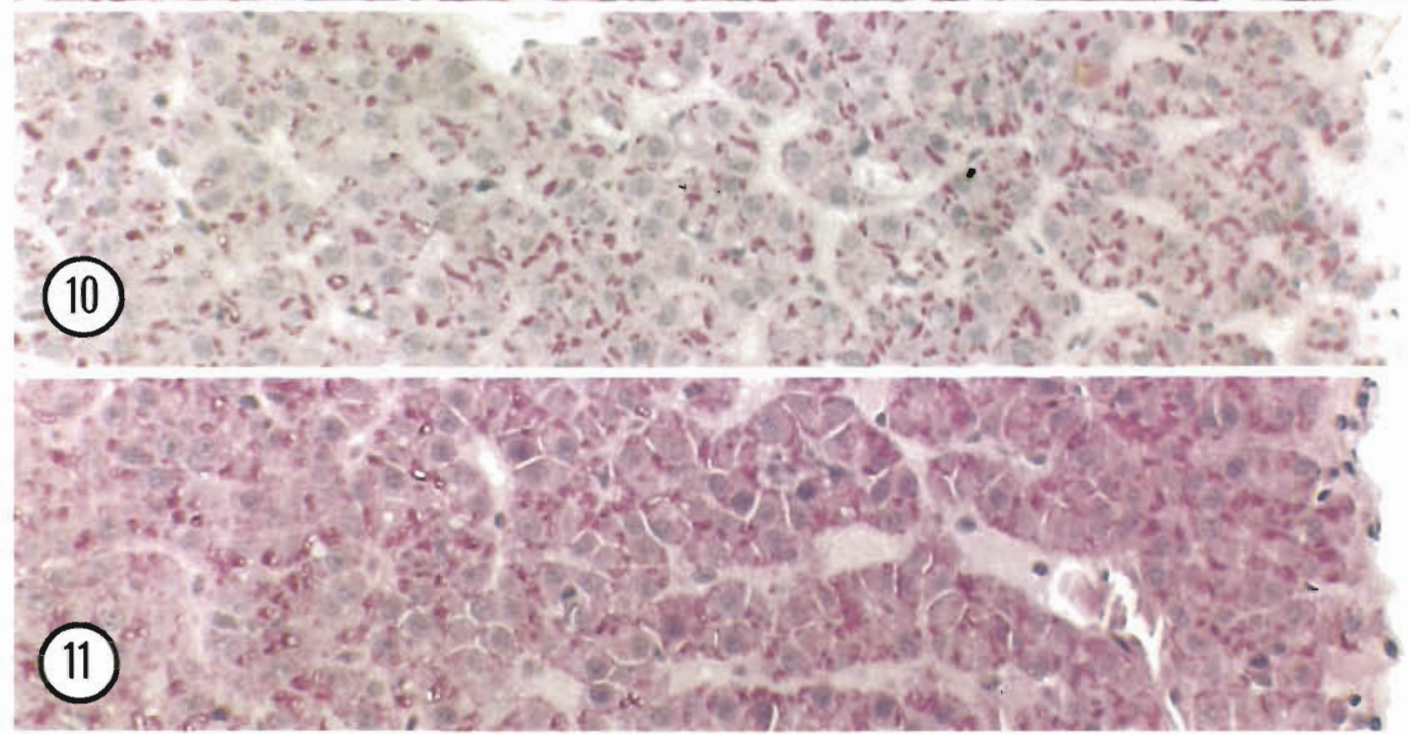

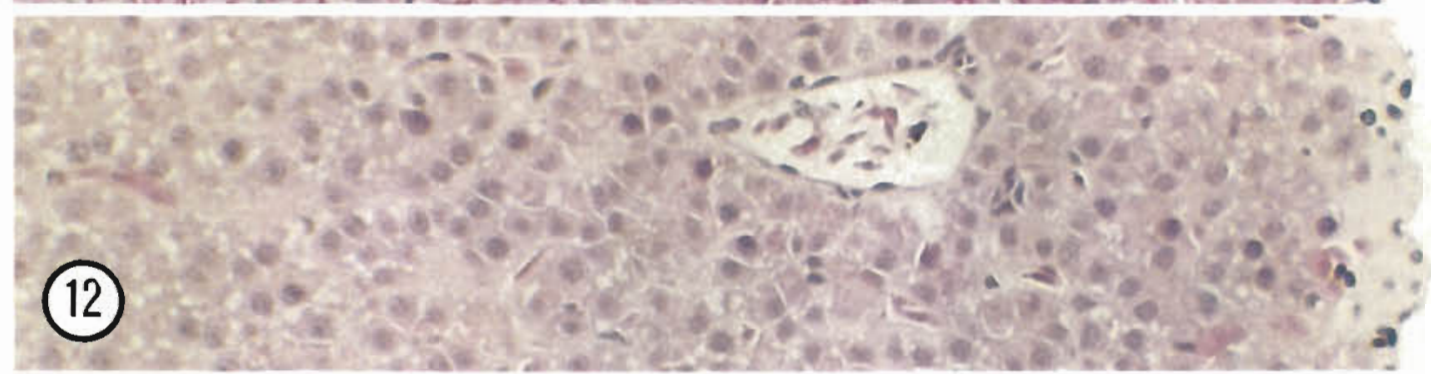


volume, i.e. shrinkage and swelling. The osmolality of an added buffer is shown by several authors to influence the result in this regard (Wood \& Luft 1965, Carson et al. 1972, 1973). However, the extent to which the fixing agent itself adds to the effective osmolality of the solution is believed to be limited (Maunsbach 1966, Hopwood 1990). The total osmolality of the fixative solutions, as measured by an osmo-meter, is therefore of limited value in explaining variations in shrinkage between fluids that contain widely different mixtures of fixing agents and additives. Notably, shrinkage is reported to be unusual with Karnovsky's fluid, despite a total osmolality as high as ca $2010 \mathrm{mOsm} \mathrm{kg}^{-1}$ (Karnovsky 1965). Furthermore, shrinkage properties are believed to be due not only to osmotic effects, but also to the direct influence of fixatives on cell respiration, membrane permeability and ion transport through the membrane (Hopwood 1990). Finally, paraffin embedding contributes considerably to the reduction in cell volume (Hampton et al. 1989), and the fixatives' abilities to protect against such changes may also be of importance. From these considerations, shrinkage limited to central portions of the slide, as observed in our study, may be interpreted as resulting more from low diffusibility of the fixating agent than from hyperosmolality. This theory corresponds well with the fact that such artifacts were more pronounced in the 2 fixatives containing glutaraldehyde, known to penetrate slowly (Hopwood 1990), than in phosphate-buffered formalin, despite the latter's higher buffer osmolality.

Acetic acid and ethyl alcohol are classified as denaturing agents (Hopwood 1990), causing protein components of the cell to precipitate. The suboptimal homogeneity of hepatocyte cytoplasm observed with Bouin's and Davidson's fluids is believed to be due to such effects, along with a substantial loss of glycogen. Simultaneously, the relatively fast penetration of these agents probably accounts for the uniform morphological appearance throughout the block.

The fact that there are a large number of fixative recipes proposed for glycogen preservation reflects that this is a much disputed area. Most investigators prefer fixatives containing alcohol and/or picric acid, e.g. Rossman's and Bouin's solutions (Manns 1958). Fish pathologists have favoured Gendre's and Davidson's fluids (Hinton et al. 1984, Hampton et al. 1985, Bullock 1989). Our findings are therefore in contrast, as none of the solutions included in this study satisfactorily demonstrated glycogen, with Bouin's and Davidson's fluid being the least effective. Attempts to explain this apparent discordance are again dubious, but fixatives with precipitating properties may be inferior to pure cross-binding ones with regard to loss of cytoplasmic contents when the glycogen load is considerable, as was the case in this investigation.
A completely objective method of evaluating and comparing fixatives does not exist. The results obtained in a comparison of fixatives will always be dependent on individual preferences by the observers. In addition, other factors, such as metabolic status, may influence the results, as demonstrated in the present study. Several efforts were made to minimize possible sources of error in this comparison. Parallel samples of liver from all fish were fixed in all fixatives, and slides were coded. Furthermore, the independent observations of several observers of the same slides were combined to produce the final results. Judgments were quantified and made comparable by means of a visual analog scale and corrected units, and finally, data were treated statistically to minimize the risk of drawing conclusions based on the law of chance.

No fixative is ideal for all tissues, and applying the results obtained in a study like this to other organs and fish species should not be done uncritically. However, for piscine liver the choice of fixative has a great influence on tissue morphology. The cells are metabolically very active, quickly undergoing substantial postmortem changes. At the same time, the compactness of the tissue offers resistance to fixative diffusion. There is relatively little connective tissue support, making it prone to shrinkage and distortion. Based on these considerations, we are tempted to suggest that a fluid which proves suitable for fixation of salmon liver may provide an acceptable basis fixative for use on most other organs.

In conclusion, $10 \%$ phosphate-buffered formalin and Davidson's fluid were found to be the fixatives best suited for histological examination of Atlantic salmon liver, as judged by evaluation of H\&E-stained sections. $10 \%$ phosphate-buffered formalin also provided the best retention of cytoplasmic glycogen. However, modification of fixative solutions, processing, and embedding procedures may lead to fur ther improvements in section quality. The ability to preserve antigens for immunohistochemical demonstration, and personnel health hazards associated with some fixatives - aspects beyond the scope of this investigation - should also be included in further search for 'the magic juice'.

Acknowledgements. We thank histotechnologists A. Kristensen, G. Babinska, and B. Saure for skillful assistance.

\section{LITERATURE CITED}

Bancroft, J. D., Stevens, A. (1975). Histopathological stains and their diagnostic uses. Churchill Livingstone, Edinburgh

Bucher, F., Hofer, R., Salvenmoser, W. (1992). Effects on treated paper mill effluents on hepatic morphology in male bullhead (Cottus gobio L.). Arch. environ. Contam. Toxicol. 23: $410-419$ 
Bullock, A. M. (1989). Laboratory methods. In: Roberts, R. J. (ed.) Fish pathology, 2nd edn. Baillière Tindall, London, $p$. $374-405$

Carson, F. L., Martin, J. H., Lynn, J. A. (1972). Ultrastructural effects of various buffers, osmolality, and temperature on paraformaldehyde fixation of the formed elements of blood and bone marrow. Texas Rep. Biol. Med. 30: $125-142$

Carson, F. L., Martin, J. H., Lynn, J. A. (1973). Formalin fixation for electron microscopy: a re-evaluation. Am. J. clin. Pathol. 59: 365-373

Couch, J. A. (1991). Spongiosis hepatis: chemical induction, pathogenesis, and possible neoplastic fate in a teleost fish model Toxicol. Pathol. 19: 237-250

Culling, C. F. A., Allison, R. T., Barr, W. T. (1985). Cellular pathology technique. Butterworths, London

Davenport, W. D., Ball, C. R. (1979). Observations on the results of specific histochemical techniques and empirical staining methods on several tissue/organ types using a variety of fixing fluids. Histopathology $3: 321-327$

Doyle, C. T., O'Leary, J. J. (1992). The search for the universal fixative or 'magic juice' (Editorial.) J. Pathol. 166: 331-332

Ferguson, H. W. (1989). Systemic pathology of fish. Iowa State University Press, Ames

Hacking, M. A., Budd, J., Hodson, K. (1978). The ultrastructure of the liver of rainbow trout: normal structure and modifications after chronic administration of a polychlorinated biphenyl Aroclor 1254. Can. J. Zool. 56: 477-491

Hampton, J. A., Clark Lantz, R., Goldblatt, P. J., Lauren, D. J., Hinton, D. E. (1988). Functional units in rainbow trout (Salmo gairdneri, Richardson) liver: II. The biliary system. Anat. Rec. 221. 619-634

Hampton, J. A., Clark Lantz, R., Hinton, D. E. (1989). Functional units in rainbow trout (Salmo gairdneri, Richardson) liver: III. Morphometric analysis of parenchyma, stroma, and component cell types. Am. J. Anat. 185: $58-73$

Hampton, J. A., McCuskey, P. A., McCuskey, R. S., Hinton, D. E. (1985). Functional units in rainbow trout (Salmo gairdneri) liver: I. Arrangement and histochemical properties of hepatocytes. Anat. Rec. 213: 166-175

Hinton, D. E. (1974). Perfusion fixation of whole bodies of fish for EM. J. Fish. Res. Bd Can. 31: 416-422

Hinton, D. E., Walker, E. R., Pinkstaff, C. A., Zuchelkowski, E. M. (1984). Morphological survey of teleost organs impor-

Responsible Subject Editor: D. E. Hinton, Davis, California, USA tant in carcinogenesis with attention to fixation. In: National Cancer Institute Monograph 65, U.S. Department of Health and Human Services, Bethesda, MD, p. 291-320

Hopwood, D. (1985). Cell and tissue fixation, 1972-1985. Histochem. J. 17: 389-442

Hopwood, D. (1990). Fixation and fixatives. In: Bancroft, J. D., Stevens, A. (eds.) Theory and practice of histological techniques, 3rd edn. Churchill Livingstone, Edinburgh, p. $21-42$

Ishikawa, T., Takayama, S. (1979). Importance of hepatic neoplasms in lower vertebrate animals as a tool in cancer research. J. Toxicol. environ. Health 5: 537-550

Ito, S., Karnovsky, M. (1968). Formaldehyde-glutaraldehyde fixatives containing trinitro-compounds. J. Cell Biol. 39: $168 \mathrm{~A}-169 \mathrm{~A}$

Jones, D. (1973). Reactions of aldehydes with unsaturated fatty acids during histological fixation. In: Stoward, P. J (ed.) Fixation in histochemistry. Chapman \& Hall, London, p. $1-45$

Karnovsky, M. J. (1965). A formaldehyde-glutaraldehyde fixative of high osmolality for use in electron microscopy. J. Cell Biol. 27: 137A-138A

Manns, E. (1958). The preservation and demonstration of glycogen in tissue sections. J. med. Lab. Technol. 15: 1-12

Maunsbach, A. B. (1966). The influence of different fixatives and fixation methods on the ultrastructure of rat kidney proximal tubule cells. II. Effects of varying osmolality, ionic strength, buffer system, and fixative concentration of glutaraldehyde solutions. J. Ultrastruct. Res. 15: 283-309

McDowell, E. M., Trump, B. F. (1976). Histologic fixatives suitable for light and electron microscopy. Arch. Pathol. Lab. Med. 100: 405-414

Mearns, A. J., Sherwood, M. J. (1974). Environmental aspects of fin erosion and tumours in southern California dover sole. Trans. Am. Fish. Soc. 103: 799-810

Shaw, B. L., Battle, H. I. (1957). The gross and microscopic anatomy of the digestive tract of the oyster, Crassostrea virginica (Gmelin). Can. J. Zool. 35: 325-347

Sinnhuber, R. O., Hendricks, J. H., Wales, J. H., Putnam, G. B. (1977). Neoplasms in rainbow trout, a sensible animal model for environmental carcinogenesis. Ann. N.Y Acad. Sci. 298: 389-408

Wood, R. L., Luft, J. H. (1965). The influence of buffer systems on fixation with osmium tetroxide. J Ultrastruct. Res. 12: $22-45$

Manuscript first received: January 6, 1993

Revised version accepted: June 3, 1993 